\title{
P202: Investigation of a cluster of invasive mold infections in a large teaching hospital
}

\author{
A Gayet-Ageron ${ }^{1 *}$, N Farquet ${ }^{1}$, E Von Dach ${ }^{1}$, C van Delden², V Camus ${ }^{1}$, Y Chalandon ${ }^{3}$, D Pittet ${ }^{1}$, A Iten ${ }^{1}$ \\ From 2nd International Conference on Prevention and Infection Control (ICPIC 2013) \\ Geneva, Switzerland. 25-28 June 2013
}

\section{Introduction}

In July 2010, we observed an increased number of invasive mold infections (IMI) in the hematology wards of our institution.

\section{Objectives}

We assessed risk factors associated with IMI in order to optimize preventive and protective measures.

\section{Methods}

Retrospective matched case-control study conducted in a 1900-bed teaching hospital between September 2008 and March 2011. Cases were defined as proven, probable, or possible according to standardized international consensus definitions. Controls were at-risk patients (onco-hematologic patients and allogeneic hematopoietic stem cell transplant recipients) hospitalized during the same time period as cases. Data were recorded by three investigators unblinded to the case-control status using a standardized case-report form. Conditional logistic regression was applied.

\section{Results}

Between November 2008 and March 2011, a total of 29 cases were identified: 6 proven $(20.7 \%), 8$ probable (27.6\%) and 15 possible cases (51.7\%); 102 controls were matched to cases. Cases had a longer hospital stay $(\mathrm{P}<0.001)$ and were exposed to a longer duration of neutropenia $(\mathrm{P}<0.001)$. They differed from controls regarding the hospitalization ward $(\mathrm{P}=0.001)$, chemotherapy use in the prior year $(\mathrm{P}=0.002)$, the existence of prior cytomegalovirus $(\mathrm{CMV})$ infection $(\mathrm{P}=0.03)$, and a higher number of examinations outside the ward before IMI diagnosis $(\mathrm{P}<0.001)$. By multivariate analysis, after adjustment for age, hospitalization ward, duration of neutropenia, and history of CMV infection, two independent factors were associated with IMI: length of hospital stay in days (OR 1.06, $\mathrm{P}=0.02)$ and the number of examinations outside the ward (OR 1.47; $\mathrm{P}=0.02)$.

\section{Conclusion}

Our results suggest that cases were more exposed to environmental fungi and specific recommendations related to patient transport within the hospital were reinforced.

\section{Disclosure of interest}

None declared.

\section{Author details}

'Infection Control Program, University Hospitals of Geneva, Geneva, Switzerland. ${ }^{2}$ Department of Surgery, Transplant service, University Hospitals of Geneva, Geneva, Switzerland. ${ }^{3}$ Service of Haematology, University Hospitals of Geneva, Geneva, Switzerland.

Published: 20 June 2013

doi:10.1186/2047-2994-2-S1-P202

Cite this article as: Gayet-Ageron et al: P202: Investigation of a cluster of invasive mold infections in a large teaching hospital. Antimicrobial Resistance and Infection Control 2013 2(Suppl 1):P202.

'Infection Control Program, University Hospitals of Geneva, Geneva,

Switzerland

Full list of author information is available at the end of the article

( 2013 Gayet-Ageron et al; licensee BioMed Central Ltd. This is an Open Access article distributed under the terms of the Creative 